https://helda.helsinki.fi

Understanding, quantifying and mapping the use of poison by commercial farmers in Namibia - Implications for scavengers' conservation and ecosystem health

\title{
Santangeli, Andrea
}

\section{6-12}

Santangeli , A , Arkumarev , V , Rust , N \& Girardello , M 2016 , ' Understanding, quantifying and mapping the use of poison by commercial farmers in Namibia - Implications for scavengers' conservation and ecosystem health ', Biological Conservation, vol. 204 , pp. 205-211 . https://doi.org/10.1016/j.biocon.2016.10.018

http://hdl.handle.net/10138/174500

https://doi.org/10.1016/j.biocon.2016.10.018

submittedVersion

Downloaded from Helda, University of Helsinki institutional repository.

This is an electronic reprint of the original article.

This reprint may differ from the original in pagination and typographic detail.

Please cite the original version. 
Title: Understanding, quantifying and mapping the use of poison by commercial farmers in Namibia Implications for scavengers' conservation and ecosystem health

Short running title: Illegal poison use by farmers

Key words: African vulture crisis; commercial farmer; Human-wildlife conflict; Modern conservation; poison use; vulture collapse;

Word count: 6000

Authors: Andrea Santangeli ${ }^{1}$, Volen Arkumarev ${ }^{2}$, Niki Rust $^{3}$ \& Marco Girardello ${ }^{4}$

\section{Affiliations:}

${ }^{1}$ The Helsinki Lab of Ornithology, Finnish Museum of Natural History, University of Helsinki, Finland

${ }^{2}$ Bulgarian Society for Protection of Birds / BirdLife Bulgaria, Yavorov complex, bl. 71, vh. 4, PO box 50, 1111 Sofia, Bulgaria

${ }^{3}$ Durrell Institute for Conservation and Ecology, University of Kent, Canterbury, CT2 7NR, UK

${ }^{4}$ Section for Ecoinformatics and Biodiversity, Department of Bioscience, Aarhus University of Aarhus-Aarhus Denmark

*Correspondence to: andrea.santangeli@helsinki.fi; tel: +358 504484443; fax: +358 294157694 


\begin{abstract}
Effective nature conservation in human-dominated landscapes requires a deep understanding of human behaviors, perceptions and values. Human-wildlife conflicts represent relatively well-studied, global-scale conservation challenges. In Africa, vulture populations are collapsing as they fall victim to poison used by livestock farmers to kill predators, but our understanding of the prevalence of this practice is still very poor. We gathered data on the prevalence of poison use in Namibia by means of questionnaires filled by commercial farmers. The data were collected and analyzed with ad-hoc quantitative methods. We quantified prevalence of poison use, determined factors associated with this practice and derived a map of its prevalence. We found that $20 \%$ of commercial farmers in Namibia used poison; farmers that owned high numbers of small stock and on large farms, and those who had suffered high livestock losses to predators, were most likely to admit to using poison. We pinpoint areas of high prevalence of reported poison use, which are largely concentrated in the south of the country. Furthermore, we report a generally positive perception of commercial farmers towards vultures, which may indicate future potential to implement bottom-up approaches for vulture conservation. Overall, the findings have important implications for prioritizing efforts to effectively tackle the African vulture crisis and preserve healthy ecosystems for the wellbeing of humans and wildlife.
\end{abstract}




\section{Introduction}

The human footprint dominates most ecosystems on Earth (Vitousek et al. 1997). Consequently, nature conservation in the Anthropocene is largely focused on improving human behavior, perceptions and values towards the environment (Kareiva \& Marvier 2012). Effective conservation typically depends on the level of understanding of human behaviors that affect biodiversity (St John et al. 2015). Illegal behaviors, such as illegal logging, poaching and poisoning of wildlife, are widespread globally and represent significant threats to a large share of biodiversity and ecosystems (Laurance et al. 2012; Ogada et al. 2016).

The use of poison as a retaliatory measure for controlling predators within a human-wildlife conflict system has come to the attention of the international conservation community for its devastating consequences on threatened taxa and ecosystems (Buechley \& Şekercioğlu 2016; Ogada et al. 2016). Use of poison to eliminate predators (e.g. by placing poisoned baits) is an illegal practice in many parts of the world and affects not only the target species (Mateo-Tomas et al. 2012), but also obligate scavengers, such as vultures, through secondary poisoning (Mateo-Tomas et al. 2012; Ogada et al. 2016). Secondary poisoning of vultures has been reported from across large regions of Africa where livestock farming coexists with predators, and is rapidly driving most vulture populations towards extinction (Buechley \& Şekercioğlu 2016; Ogada et al. 2016). In practice, we are witnessing an "African vulture crisis" (Ogada et al. 2016).

The mutualism between humans and vultures has a history going back millennia, whereby vultures have been providing important ecosystem services for the benefits of human wealth and health (Moleón et al. 2014). For example, vultures contribute to the disposal of human byproducts (urban organic waste; Gangoso et al. 2013) and carcasses of livestock and wild animals, thereby preventing the spread of diseases, such as ebola, anthrax, rabies (Monroe et al. 2015; Sekercioğlu et al. 2016). Vultures were also found to contribute to reduced green-house-gas emissions by limiting transportation needed to transfer byproducts (Morales-Reyes et al. 2015). As vulture populations are plummeting across Africa, largely due to poisoning (Ogada et al. 2016), their associated services are also being lost and the consequences for ecosystems and human wellbeing could be severe (Buechley \& Şekercioğlu 2016). African governments have recently realized the scale and magnitude of the issue and have committed to take actions to prevent vulture poisoning with the 
approval of a resolution on wildlife crime and trade (Ogada et al. 2016; http://web.unep.org/unea/tableresolutions-adopted-unea-2).

Now that the poisoning threat to vultures is gaining momentum in the political agenda, it is timely and relevant that this threat is quantified and mapped and that the factors triggering poison use are deeply understood. This would provide the evidence base for developing and implementing successful conservation strategies (Knight et al. 2010).

In Namibia, more than $90 \%$ of the country's wildlife, including carnivores, is found on private farmland (Krugmann 2001), highlighting the potential for human-wildlife conflict (Lindsey et al. 2013) and the conservation challenges in this complex socio-ecological landscape. The use of chemical poisons, including the use of pesticides off-label, is illegal in Namibia and can pose a serious threat to the environment and people (UNEP 2016). Unfortunately, using poison to eradicate predators represents among the most readily available solution for farmers (Mateo-Tomas et al. 2012). The extent and underpinnings of poison use, a practice that carries disproportionate consequences for scavengers' conservation and ecosystem health, are however poorly understood in Namibia and beyond.

With this study, we aim to fill this gap in knowledge by investigating the use of poison by commercial farmers in Namibia. Specifically, we first aim to understand the general perception of commercial farmers towards predators and vultures. Second, we quantify the overall proportion of farmers using poison in Namibia. Third, we identify the social and ecological factors that influence the use of poison by farmers. Fourth, we map the extent of poison use by farmers across the country.

\section{Methods}

Protocol for data collection

We compiled a series of relevant questions to characterize and quantify the use of poison by farmers in Namibia (see below and Supporting Material Appendix S1). The questionnaire was tested with colleagues before the start of the data collection. There was no need for further adjustments of the survey after starting 
the systematic data collection. All questionnaires were administered in person by AS or VA. Each questionnaire lasted about 10 minutes, was administered in English and respondents were free to decide if they wanted to fill it themselves or if they wanted us to read them the questions and write the answers. We approached commercial farmers in Namibia between September and November 2015. To maximize efficiency in data collection, we combined driving along roads and stopping at farms ( $\mathrm{n}=32$ questionnaires) with spending a few days in an agricultural retail chain stores $(n=380)$. These stores are regularly visited by farmers and are present in each of the largest towns across Namibia. We used opportunistic sampling by asking all farmers we could locate at their farm or in the retail shops to participate to our survey. We briefly explained that the project was aimed at understanding land management decisions and its implications to wildlife, and we introduced ourselves as neutral (i.e. with no link to local government) researchers. We also explained that the questionnaire was anonymous.

Only a minority (approximately $<5 \%$ ) of approached farmers declined participation, mostly because they lacked time. We believe that a very negligible proportion of farmers, if at all, declined participation because of the topic. This is because we introduced the study in a broad context (see above) and also because farmers appeared to be open to discussing topics on predator control and the various means, including using poison, by which this is achieved. We briefly explained that the project aimed to understand land management decisions and its implications to wildlife. Overall, questionnaires were administered to a total of 412 commercial farmers (see below) distributed rather homogeneously across Namibia's commercial farmland (Fig. 1).

General non-sensitive questions

The survey (Supporting Material Appendix S1) included a first part where 19 questions related to basic demography (e.g. sex, age, \% income derived from livestock farming), to the farming context (e.g. location and size of the farm, type and number of livestock farmed), to the relationship farmers have with their farmworkers, with game and with predators, as well as farmers knowledge of vultures (e.g. their status, threats, ecological role) and perceptions towards vultures (e.g. whether vultures are useful to farmers; see 
each related question in Supporting Material Appendix S1). The above questions were selected based on their potential relationship to the use of poison (see rationale below). For the questions related to relationship with farmworkers, game and predators, and perception towards vultures, respondents were asked to indicate their agreement with a statement using a five-point Likert scale. The scale ranged from strongly agree, agree, neutral, disagree or strongly disagree for questions on relationship with farmworkers, game and predators, whereas for perception towards vultures, neutral was replaced by "don't know" in the Likert scale.

We also asked respondents to quantify the percentage of livestock they reportedly lost during the past year, the perceived main cause for that loss, and also how often do they see vultures on their farm. All the above questions were used to characterize the context in which certain behaviors occurred, such as the potential intensity of human-wildlife conflict (Romañach et al. 2007) or the perception and attitude of farmers towards vultures, among others. Moreover, we also asked respondents to estimate the percentage of occurrence of their peers' behavior, such as killing predators or vultures, using poison to kill predators or vultures. These peers' estimates aimed to verify that the frequency of behaviors obtained from the estimates that farmers provided of their peers' behavior are consistent with the values that farmers provided on their own behavior using the RRT technique (see below and St John et al. (2012)). Not all the surveys' descriptive questions were fully completed (see sample sizes from captions of Fig. S1-4).

Randomised response technique questions

We used the randomized response technique (RRT), a survey method that has been used to obtain accurate estimates of the prevalence of sensitive behaviors (Nuno \& St John 2015). We chose an RRT design that allows for the highest statistical efficiency: the "forced response" RRT (Lensvelt-Mulders et al. 2005; Nuno $\&$ St John 2015). The choice for this specific technique among alternatives (e.g. nominative technique) was driven by its suitability for use across a range of respondents with different education level. Moreover, it allows modeling the relationship between the occurrence of the sensitive behavior and explanatory variables possibly associated to that behavior (Nuno \& St John 2015). 
The four sensitive questions were: "In the last 12 months did you purposefully kill any predator?"; "In the last 12 months did you purposefully kill any vulture?"; "In the last 12 months did you use poison to kill predators?"; "Would you use poison to kill a predator, if you had lost livestock to predators?". We used a time period constrained to the past 12 months from the time when the survey was filled as it represents a good balance between minimizing recall inaccuracy but at the same time allow a long enough time span for the behavior to have occurred (St John et al. 2012).

We applied the technique by presenting to the respondent a bag with ten balls in it. Out of the ten balls, eight were blue, one was red and one white. The respondent was asked to privately (i.e. out of sight of the interviewer) draw a ball from a bag at the beginning of each of the four sensitive questions (see below for description of the questions and Appendix S1 for instructions on the RRT given to respondents). The ball was placed back to the bag after each drawing. Depending on the ball color drawn, the respondent was instructed to answer truthfully to the sensitive question (i.e. "yes" or "no", depending of what the truth was) if the blue ball (eight out of ten) was drawn; or to give a prescribed answer irrespective of what the truth was in the other cases, i.e. answer "yes" if the white ball was drawn, answer "no" if the red ball was drawn. The color of the ball was never revealed to the interviewer so that a certain level of anonymity in the response by the respondent was retained. However, by knowing the probabilities of respondents being required to answer truthfully and the probability of the two forced answers, it is possible to derive an aggregate estimate of the frequency of the sensitive behavior. Respondents were carefully instructed regarding the technique and the protocol for answering the sensitive questions by the interviewer directly (e.g. by providing a simple example) and by presenting a short and simple text explaining the technique and the protocol for answering the questions (see Supporting Material Appendix S1).

\section{Statistical analyses}

In order to quantify the proportion of farmers that reported undertaking each specific RRT behavior, we used the simple formula provided by Hox \& Lensvelt-Mulders (2004; see also St John et al. (2012)). We then focused on the specific question (aim 3, see above) related to the relationship between poison use by farmers 
and a selection of relevant socio-environmental factors. In doing so, we selected a complementary set of variables.

Below we provide a description of each of the 13 variables included in the model as well as the rationale for their inclusion. Farm size, as well as total stock number and number of small stock (including livestock and also game, if the farmer is a game farmer) were included with the rationale that managing and protecting livestock from predators may be more challenging on large farms, or on farms with high stock numbers, particularly stock of small size which can be often predated by small predators (i.e. black-backed jackals, Canis mesomelas, Caracals, Caracal caracal) common across Namibia's commercial farmland (Lindsey et al. 2013). Age was included considering two classes, young and old (below 45 and above 46 years of age, respectively), and was aimed to test whether there are signs of intergeneration differences in the use of poison. Percentage of income coming from livestock farming (over the farmer's total income; hereafter \% income from farming) was also included because farmers where most income comes from livestock may be more likely to use poison to limit livestock depredation (Lindsey et al. 2013). Percentage of livestock loss (hereafter \% stock lost) as well as the main cause of loss (whether the loss was mainly due to predation or not; hereafter named cause of loss) depict the extent of the human-wildlife conflict occurring at the farm level (Lindsey et al. 2013). Similarly, distance to the closest national park was used a proxy for the potential human-wildlife conflict, because national parks in Namibia support high densities of predators (such as lions Panthera leo, spotted hyenas Crocuta crocuta) that sometimes roam outside of the parks and predate on livestock (this occurs e.g. at the farms bordering the southern boundary of the Etosha National Park; pers. comm. from farmers in that area). We then included a variable depicting the relationship between the farmer and farmworkers (hereafter relationship to farmworkers). This was obtained from the answers (on the Likert scale, from -2 that is strongly disagree, to +2 strongly agree) to the specific statement "I get along well with my workers" (see question 12.a in Supporting Material Appendix S1). Across commercial farmlands of Namibia, there has been reported a somewhat difficult relationship between farmer and farmworker, which may result in increased human-wildlife conflicts due to poor livestock management practices (Rust et al. 2016). Similarly, a negative perception towards game and predators may entail higher frequency of poison use, owing to possible human-wildlife conflicts (predators) and to a negative perception of wildlife in 
general (game). Thus we included in the model two variables based on answers (on Likert scale) to two related statements: "I like having game on my farm" and "I like having predators on my farm" (hereafter relationship to game and relationship to predators; question 13.a and 14.a in Supporting Material Appendix S1). Finally we included a variable depicting the frequency that farmers see vultures on their farm (hereafter frequency vulture sighting) and a variable depicting the perception of farmers towards vultures (hereafter perception towards vultures; see question 17 and 18.f in Supporting Material Appendix S1). The latter included answers to the statement: "Vultures are useful to have on the farm". One might expect that if farmers value vultures as useful animals on the farm, they may refrain from using poison.

Other variables from the questions listed in the questionnaire have been excluded from the model on poison use either because they were deemed not relevant in explaining use of poison by farmers or because they were highly correlated with any of the 13 variables listed above and already included (see Fig. S1). Consequently, the 13 variables used were largely un-correlated. All of them were used as continuous variables beside age and cause of livestock loss (categorical with two levels).

The relationship between poison use and the 13 socio-environmental predictors was analyzed using Generalized Linear Modelling (GLM). Total sample size was 335 (i.e. the sample of fully completed questionnaires out of the 412 total, see above). The error structure associated with the model was assumed to be binomial with a link function appropriate for randomized responses (van den Hout et al. 2007). This consists of a modified logit link function that incorporates known probabilities of the forced RRT responses (van den Hout et al. 2007). We run all model combinations using the 13 predictors. The models were ranked using the Bayesian Information Criterion (BIC) and the BIC weight for each model was estimated following (Burnham \& Anderson 2002). We constructed a 95\% confidence set of models by starting with the highest BIC weight and adding to the model with the next highest weight until the cumulative sum of weights exceeded 0.95. As no single model was clearly superior to the others in the set, we used a multi-model inference approach based on model averaging (Burnham \& Anderson 2002). The predictor coefficients were calculated as the average of all the regression coefficients within the confidence set, weighted by their BIC weights. The relative importance of individual predictors was calculated using the ratio of absolute values of the $t$ statistics for unstandardized predictors (Cade 2015). This metric of relative importance was also 
averaged across the $95 \%$ confidence set, weighted by BIC weights. We also investigated the extent of spatial autocorrelation in the residuals of the models using spatial correlograms. However, no significant spatial autocorrelation was detected. Finally, we used model-averaged predicted values from the $95 \%$ confidence set to map the probability of poison use on commercial farms across Namibia. The map was generated by interpolating predicted values using the inverse distance squared weighting interpolation method (Neteler \& Mitasova 2013). All models were fitted using the RRreg (Heck \& Moshagen 2016) package in R 3.3.0 (R Core Team 2016). Inverse distance squared weighting interpolation was performed using the v.surf.idw GRASS GIS module (Neteler \& Mitasova 2013).

\section{Results}

Farming context

Among the 412 respondents, $93 \%$ were males and $67 \%$ were over 45 years of age. The average farm size was 8403 ha with an average of 705 small livestock (goat and sheep) and an average total livestock of 971 animals. $43 \%$ of respondents farmed a mixture of cattle, game and/or small stock, whereas 21 and 20\% farmed cattle or livestock and game, respectively. A large percentage (74\%) of respondents were full-time farmers, with $47 \%$ of respondents having more than $90 \%$ of their income coming from livestock farming (see Fig. S2). Respondents had an overall positive relationship with their farmworkers, as $95 \%$ of respondents declared that they got along well with their workers. However, problematic issues also emerged, as $70 \%$ of farmers stated their workers sometimes did not follow their orders, and $41 \%$ admitted their workers sometimes poached or stole from them (Fig. S2).

Farmers' perception towards game, predators and vultures 
The perception of the responding farmers towards game animals was overall very positive, with a large proportion of them being happy to share their land with game (97\% of farmers) and take active steps to conserve game (93\%; Fig. S3).

Among the respondents, only 5\% (20 cases) declared no stock losses (due to any cause) during the previous year, whereas $51 \%$ lost $1-10 \%$ of their stock, and $27 \%$ of respondents lost over $10 \%$ of their stock. Predators were identified as the main cause for the loss of stock by $50 \%$ of respondents. Farmers' perception towards predators was rather negative. Most farmers (79\%) did not like to have predators on their farm and $67 \%$ believed that predators belong only in the national parks (Fig. S4).

Most respondents had a relatively good knowledge of the ecological value of vultures and had a positive perception towards these birds. For example, $96 \%$ farmers agreed that vultures were useful to have on the farm, and $95 \%$ of them agreed that vultures disposed of carcasses and prevented the spread of diseases, whereas a minority (11\%) believed that vultures could kill livestock (Fig. S5). Moreover, almost all farmers (98\%) knew that vultures can be killed by poisoned carcasses. Respondents' knowledge on vulture population trends in Namibia was rather mixed, with $42 \%$ of them agreeing that vulture populations are increasing in Namibia. Interestingly, more farmers stated that vulture populations on their farm are increasing (68\%) rather than declining (32\%; Fig. S5).

Estimated proportion of farmers behaviors

We used the full sample of 412 questionnaires to calculate the occurrence of the four sensitive behaviors using the appropriate statistical framework required for the RRT. About three out of four farmers (77\%) admitted to have purposefully killed a predator in the past year, whereas none killed purposefully any vulture according to the estimates derived from the RRT (Fig. 2). Moreover, one out of five commercial farmers (20\%) admitted to have used poison to kill predators over the past year, and 34\% admitted that they would use poison to kill a predator if they had lost livestock to predators (Fig. 2).

When farmers were asked to estimate their peers' behavior using similar questions to the RRT, the results were very similar. Respondents estimated that $67 \%$ of their peers purposefully killed a predator without the 
required permit over the past year, 3\% of their peers were estimated to have purposefully killed vultures (Fig. S6). Moreover, $22 \%$ of farmers' peers were estimated to have used poison to kill predators, and only $2 \%$ to have used poison to kill vultures over the past year (Fig. S6).

\section{Factors related to poison use}

The model averaged results (Table 1) and variables' relative importance (Fig. 3) suggest that there were several factors that were related to use of poison by commercial farmers in Namibia. Use of poison was best related to factors describing the extent of potential human-wildlife conflict. Specifically, use of poison was highest among farmers with the largest number of small stock (i.e. sheep and goat) or overall stock (including livestock and game), as well as farmers that lost the highest number of livestock to predators and for which predation was identified as the main cause of livestock loss (Table 1 and Fig. 3). Farmers that reported a negative relationship with their farmworkers and with a negative perception towards predators and game were most likely to have used poison. Moreover, farmers owing a larger farm were more likely to use poison than farmers owing a small farm. Other variables, such as the $\%$ of income coming from livestock farming, frequency of vultures seen on the farm and farmers perception towards vultures, as well distance to the closest national park and age of the farmer, had a low relative importance compared to the other variables (Fig. 3), indicating their weak relationship with poison use by farmers.

Spatial variation in poison use

We derived a map showing the spatial variation in the interpolated proportion of commercial farmers using poison across Namibia (Fig. 4). The prevalence of poison use was not evenly distributed across Namibia. Poison use was most prevalent across the southern half of the country, particularly towards the eastern areas of southern Namibia. Within this area of high prevalence of poison use, a few distinct hotspots (where close to $50 \%$ of farmers were estimated to use poison; orange to red areas in Fig. 4) are also visible. Poison use was least prevalent in the northern half of the country, with some exceptions such as westernmost and northernmost areas (e.g. the one adjacent to the southern border of Etosha National Park). 


\section{Discussion}

Here we have taken an interdisciplinary approach by combining social and ecological data collected with specific questionnaire survey technique with appropriate quantitative methods to characterize, quantify and map the use of poison by commercial farms across Namibia. Most previous studies (a selection of which could be found in Nuno \& St John (2015) using quantitative techniques (such as RRT) to investigate the extent of illegal behavior have been restricted in terms of spatial coverage and amount of questionnaires collected due to obvious logistic constraints. Here we gathered a uniquely large amount of questionnaire data and, to our best knowledge, for the first time at the national level we could map the extent of illegal behavior using a technique that yields reliable estimates of the prevalence of an illegal behavior.

Our results indicate that the human-wildlife conflict is yet unresolved among Namibia's commercial farmers, as their perceptions towards predators are, not surprisingly, broadly negative. This is in line with previous findings (Lindsey et al. 2013). That said, farmers reportedly had generally positive perceptions towards vultures and their ecological role. Nevertheless, about one out of five interviewed farmers admitted to having used poison, and one out of three said they would use poison in the future to limit human-wildlife conflict. Farmers having large numbers of small stock, large farms, and those who reportedly suffered high livestock losses to predators were most likely to report using poison. Livestock scattered over a large farm area of thousands of hectares can be difficult to protect from predators, thereby potentially facilitating predation and consequently the use of poison, as our results indicate. We also found indication that the use of poison may be driven by problematic relationships between farmer and farmworkers. This is in line with recent findings suggesting that socioeconomic inequalities between farmers and their workers may exacerbate the humanwildlife conflict in Namibia (Rust et al. 2016). Poison use was most prevalent in large areas of southern Namibia where small stock farming is most common due to arid conditions (Schumann et al. 2012). In this environment where farming is very challenging due to ecological conditions, the added losses from predation may have disproportionate consequences for an individual farmer. Therefore, addressing the use of poison here represents an important social and environmental challenge. 
A previous assessment done in the mid-1980s across Namibia reported a much higher prevalence of poison use by farmers in the north (30\% of farmers), central (45\%) and southern (>80\%) part of the country compared to that of the present study. While the differences in the prevalence of poison use between the two studies may be due to the use of different approaches, the apparently large decrease in poison use by farmers may also be due to targeted developments. Among these, the recent resolution by the Veterinary Council of Namibia to ban the prescription of strychnine, which is also no longer imported to the country (Simmons et al. 2015). Moreover, the recent shift from livestock to game farming for trophy hunting and tourism, e.g. through conservancies, might have alleviated the human-wildlife conflict and consequently the use of poison (Schumann et al. 2008).

After the routine interviews were completed, several farmers reported usage of different poisonous substances. The most used poisons were carbamate pesticides such as carbofuran and aldicarb, but also strychnine, which is nowadays banned for use in Namibia. Aldicarb was used by $83 \%$ of the farmers who stated the type of the poison they used $(n=66)$. It causes secondary poisoning and has severe effects on vultures (Botha et al. 2015). Nearly $88 \%$ of the farmers $(n=65)$ were using poison baits. Baits were mainly small pieces of meat or fat which they hide in bushes or small holes in the ground. Other $12 \%$ admitted that they administer poison on whole carcasses of livestock killed by predators.

The number of studies that investigate the prevalence of illegal behaviors that threaten wildlife is rapidly growing (Nuno \& St John 2015). However, to our best knowledge, no previous study has focused on a specific practice, such as using poison that, through secondary effects, can impact non-target species and trigger cascading effects through the entire ecosystem (Buechley \& Şekercioğlu 2016). The wide spatial distribution as well as the overall prevalence of poison use and the intention of using poison are worrisome, particularly for conserving vultures in southern Namibia. In this region, human-wildlife conflict with small stock is prevalent due to predation by small size predators (mainly black-backed jackals and caracals; Schumann et al. (2012)). The situation appears particularly critical in the eastern part of Southern Namibia, where an important stronghold of the national population of the IUCN critically endangered White-backed vulture (Gyps africanus) occurs (Simmons et al. 2015) in a landscape where poison use is most prevalent (Fig. 4). 
Our findings indicate that conservation interventions, such as strict regulation, restriction and control over the distribution and usage of pesticides that are used off-label, as well as social marketing, education campaigns and possibly promotion of vulture focused ecotourism, should largely focus on the large farms in southern Namibia wherever possible. One of these farms may contain several nests of, for example, the White-backed vulture. This underscores an important opportunity for efficiently implementing on-the-ground conservation interventions, because the number of farmers involved in this illegal activity is limited (Brown 1991; Knight et al. 2010). Moreover, the positive perception towards vultures, but also the lack of awareness of vulture declines, indicate that there may be scope for designing and implementing solutions that would allow farmers to minimize livestock predation while preserving healthy vulture populations. Large-scale education campaigns on best farming practices such as use of calving camps, use of effective corrals or synchronized calving might increase livestock survival and reduce the prevalence of poison use. In the arid southern regions of Namibia, farmers already successfully use electric fences to protect their livestock. This practice can severely reduce human-predator conflicts and the use of poison, but its implementation may be limited by the high costs and local conditions and it also has negative effects on the free movement of wildlife (Rust et al. 2015).

As humans are often the cause of many environmental problems, it is within us that rests the hope for implementing conservation solutions. Influencing human behavior represents a core part of the solution, but for this to take place, the prevalence and distribution of the behavior and associated factors underlying its occurrence must be deeply understood. Here we provide such understanding of a practice, such as the use of poison, which can have large scale and long-term repercussions on ecosystems and human health and wealth (Mateo-Tomas et al. 2012; Ogada et al. 2012). The approach and findings presented here are instrumental for prioritizing conservation efforts towards areas of high threat in Namibia, and potentially replicating this study to other areas in Southern Africa where similar challenges occur (Ogada et al. 2016). Ultimately, the implications of this study span far beyond the boundaries of Namibia and the studied system. As African countries are increasingly committing to tackle the vulture plight due to indiscriminate use of poison, conservation scientists can play a key role in delivering the knowledge and evidence base for implementing 
effective conservation actions before it is too late (Ogada et al. 2016). We believe this work provides a first step towards that direction.

\section{Acknowledgements}

AS is grateful to the Kone foundation and the Mohamed bin Zayed Species Conservation Fund for financially supporting this study. We also thank Holger Kolberg and Peter Bridgeford from Vultures Namibia for assistance and support in Namibia, and all farmers who participated to the survey.

\section{Reference list}

Botha, C. J., H. Coetser, L. Labuschagne, and A. Basson. 2015. Confirmed organophosphorus and carbamate pesticide poisonings in South African wildlife (2009-2014). Journal of the South African Veterinary Association 86:1 - 4 .

Brown, C. J. 1991. Declining martial Polemaetus bellicosus and tawny Aquila rapax eagle populations and causes of mortality on farmlands in central Namibia. Biological Conservation 56:49-62.

Buechley, E. R., and Ç. H. Şekercioğlu. 2016. The avian scavenger crisis: Looming extinctions, trophic cascades, and loss of critical ecosystem functions. Biological Conservation 198:220-228.

Burnham, K. P., and D. R. Anderson 2002. Model selection and multimodel inference: a practical information-theoretic approach. Springer, New York.

Cade, B. S. 2015. Model averaging and muddled multimodel inferences. Ecology 96:2370-2382.

Gangoso, L., R. Agudo, J. D. Anadón, M. de la Riva, A. S. Suleyman, R. Porter, and J. A. Donázar. 2013. Reinventing mutualism between humans and wild fauna: insights from vultures as ecosystem services providers. Conservation Letters 6:172-179.

Heck, D. W., and M. Moshagen. 2016. RRreg: Correlation and Regression Analyses for Randomized Response Data.

Hox, J., and G. Lensvelt-Mulders. 2004. Randomized response analysis in Mplus. Structural Equation Modeling-a Multidisciplinary Journal 11:615-620. 
Kareiva, P., and M. Marvier. 2012. What Is Conservation Science? BioScience 62:962-969.

Knight, A. T., R. M. Cowling, M. Difford, and B. M. Campbell. 2010. Mapping human and social dimensions of conservation opportunity for the scheduling of conservation action on private land. Conservation Biology 24:1348-1358.

Krugmann, H. 2001. Fundamental issues and the threats to sustainable development in Namibia. Directorate of Environmental Affairs, Ministry of Environment and Tourism, Windhoek, Namibia.

Laurance, W. F., et al. 2012. Averting biodiversity collapse in tropical forest protected areas. Nature 489:290-294.

Lensvelt-Mulders, G., J. J. Hox, and P. G. M. Van der Heijden. 2005. How to improve the efficiency of randomised response designs. Quality \& Quantity 39:253-265.

Lindsey, P. A., C. P. Havemann, R. Lines, L. Palazy, A. E. Price, T. A. Retief, T. Rhebergen, and C. Van der Waal. 2013. Determinants of Persistence and Tolerance of Carnivores on Namibian Ranches: Implications for Conservation on Southern African Private Lands. Plos One 8.

Mateo-Tomas, P., P. P. Olea, I. S. Sanchez-Barbudo, and R. Mateo. 2012. Alleviating human-wildlife conflicts: identifying the causes and mapping the risk of illegal poisoning of wild fauna. Journal of Applied Ecology 49:376-385.

Moleón, M., J. A. Sánchez-Zapata, A. Margalida, M. Carrete, N. Owen-Smith, and J. A. Donázar. 2014. Humans and Scavengers: The Evolution of Interactions and Ecosystem Services. BioScience 64:394-403.

Monroe, B. P., J. B. Doty, C. Moses, S. Ibata, M. Reynolds, and D. Carroll. 2015. Collection and Utilization of Animal Carcasses Associated with zoonotic Disease in Tshuapa District, the Democratic Republic of the Congo, 2012. Journal of Wildlife Diseases 51:734-738.

Morales-Reyes, Z., et al. 2015. Supplanting ecosystem services provided by scavengers raises greenhouse gas emissions. Scientific Reports 5:7811.

Neteler, M., and H. Mitasova 2013. Open source GIS: a GRASS GIS approach. Springer Science \& Business Media, New York, USA.

Nuno, A., and F. A. V. St John. 2015. How to ask sensitive questions in conservation: A review of specialized questioning techniques. Biological Conservation 189:5-15. 
Ogada, D., P. Shaw, R. L. Beyers, R. Buij, C. Murn, J. M. Thiollay, C. M. Beale, R. M. Holdo, D. Pomeroy, N. Baker, S. C. Krüger, A. Botha, M. Z. Virani, A. Monadjem, and A. R. E. Sinclair. 2016. Another Continental Vulture Crisis: Africa's Vultures Collapsing toward Extinction. Conservation Letters 9:89 - 97.

Ogada, D. L., M. E. Torchin, M. F. Kinnaird, and V. O. Ezenwa. 2012. Effects of Vulture Declines on Facultative Scavengers and Potential Implications for Mammalian Disease Transmission. Conservation Biology 26:453-460.

Romañach, S. S., P. A. Lindsey, and R. Woodroffe. 2007. Determinants of attitudes towards predators in central Kenya and suggestions for increasing tolerance in livestock dominated landscapes. Oryx 41:185-195.

Rust, N. A., M. T. Nghikembua, J. J. W. Kasser, and L. L. Marker. 2015. Environmental factors affect swing gates as a barrier to large carnivores entering game farms. African Journal of Ecology 53:339-345.

Rust, N. A., J. Tzanopoulos, T. Humle, and D. C. MacMillan. 2016. Why Has Human-Carnivore Conflict Not Been Resolved in Namibia? Society \& Natural Resources 29:1079-1094.

Schumann, B., J. L. Walls, and V. Harley. 2012. Attitudes towards carnivores: the views of emerging commercial farmers in Namibia. Oryx 46:604-613.

Schumann, M., L. H. Watson, and B. D. Schumann. 2008. Attitudes of Namibian commercial farmers toward large carnivores: The influence of conservancy membership. South African Journal of Wildlife Research 38:123-132.

Sekercioğlu, C. H., D. Wenny, and C. J. Whelan 2016. Why Birds Matter? University of Chicago Press, Chicago, USA.

Simmons, R. E., C. J. Brown, and J. Kemper 2015. Birds to watch in Namibia: red, rare and endemic species. Ministry of Environment and Tourism and Namibia Nature Foundation, Windhoek, Namibia.

St John, F. A. V., A. M. Keane, G. Edwards-Jones, L. Jones, R. W. Yarnell, and J. P. G. Jones. 2012. Identifying indicators of illegal behaviour: carnivore killing in human-managed landscapes. Proceedings of the Royal Society B-Biological Sciences 279:804-812.

St John, F. A. V., C.-H. Mai, and K. J. C. Pei. 2015. Evaluating deterrents of illegal behaviour in conservation: Carnivore killing in rural Taiwan. Biological Conservation 189:86-94. 
UNEP. 2016. Healthy Environment, Healthy People. Thematic report. Ministerial policy review session. Second session of the United Nations Environment assembly of the United Nations Environment Programme. United Nations Environment Programme, Nairobi, Kenya.

van den Hout, A., P. G. M. van der Heijden, and R. Gilchrist. 2007. The logistic regression model with response variables subject to randomized response. Computational Statistics \& Data Analysis 51:6060-6069.

Vitousek, P. M., H. A. Mooney, J. Lubchenco, and J. M. Melillo. 1997. Human domination of Earth's ecosystems. Science 277:494-499. 
Tables:

Table 1. The relationship between poison use by commercial farmers in Namibia and 13 socio-ecological factors.

variable Coefficient SE Lower.CI Upper.CI Question No.

\begin{tabular}{lccccc}
\hline Intercept) & $-3,41$ & 1,34 & $-6,05$ & $-0,78$ & \\
N. small stock & 0,32 & 0,12 & 0,09 & 0,54 & $9 . \mathrm{a}$ \\
\% stock lost & 0,08 & 0,06 & $-0,04$ & 0,20 & 15 \\
Total stock N. & 0,26 & 0,36 & $-0,44$ & 0,96 & $9 . \mathrm{d}$ \\
Cause of loss (predator) & 0,65 & 0,43 & $-0,19$ & 1,48 & 16 \\
Relationship to game & $-0,29$ & 0,24 & $-0,76$ & 0,19 & $13 . \mathrm{a}$ \\
Relationship to farmworkers & $-0,30$ & 0,20 & $-0,68$ & 0,09 & $12 . \mathrm{a}$ \\
Farm size & 0,21 & 0,24 & $-0,25$ & 0,68 & 10 \\
Relationship to predators & $-0,56$ & 0,51 & $-1,56$ & 0,43 & $14 . \mathrm{a}$ \\
\% income from farming & 0,00 & 0,01 & $-0,01$ & 0,02 & 6 \\
Distance to National Park & 0,00 & 0,00 & $-0,01$ & 0,01 & \\
Frequency vulture sighting & $-0,04$ & 0,15 & $-0,34$ & 0,25 & 17 \\
Perception towards vultures & 0,20 & 0,30 & $-0,38$ & 0,79 & $18 . \mathrm{f}$ \\
Age (old) & 0,17 & 0,45 & $-0,72$ & 1,06 & 3
\end{tabular}

Reported coefficients, standard errors and $95 \%$ upper and lower confidence intervals were derived from a model-averaging procedure using the $95 \%$ confidence set of models built using the 13 variables and ranked using the BIC (Bayesian Information Criterion). All variables were included as continuous, with the exception of two categorical variables with two levels each: Cause of loss (whether stock loss was related to predator or other cause; using other cause as the reference category); Age (young vs. old; using young as the reference category). Question No. refers to the number and code for the questions and sub-question as shown in the original survey (Appendix S1). Distance of the farm to the nearest National Park was not included in the survey as it was derived a posteriori. The option to choose between four age classes was given in the questionnaire, but in the models, and results presented here, age was reclassified into 2 discrete classes (young $\leq 45$; old $\geq 46$ ). Similarly, Cause of loss was presented in the survey with ten options to choose from, but here and in the model it is presented as loss caused by predators vs. all other causes. 
Figure legends:

Figure 1. Map showing the location of the 412 commercial farms (black dots) across Namibia that participated in the survey. Commercial farmland areas are shown in light grey and National Parks in dark grey.

Figure 2. Randomised Response Technique estimates of the proportion of farmers that killed a predator, killed a vulture, used poison to kill a predator (used poison) over the past 12 months, and would use poison to kill a predator if had lost livestock to predators.

Figure 3. Relative importance of each socio-ecological variable as it relates to poison use by commercial farmers in Namibia (see also Table 1 for more details on the direction and strength of the effect of each variable). Variable importance was calculated as the ratio of the $t$ statistics included within individual candidate models. Values were then averaged across the $95 \%$ confidence set weighted by model weights.

Figure 4. Probability of poison use across commercial farms in Namibia. The map was derived using inverse distance weighting interpolation of model-averaged predictions from $95 \%$ confidence set (see methods and Table 1) relating poison use (estimated using the Randomised Response Technique) and socio-ecological factors. White areas in the map are not owned by commercial farmers (e.g. communal farming areas). Grey areas represent National Parks. 
Figures:

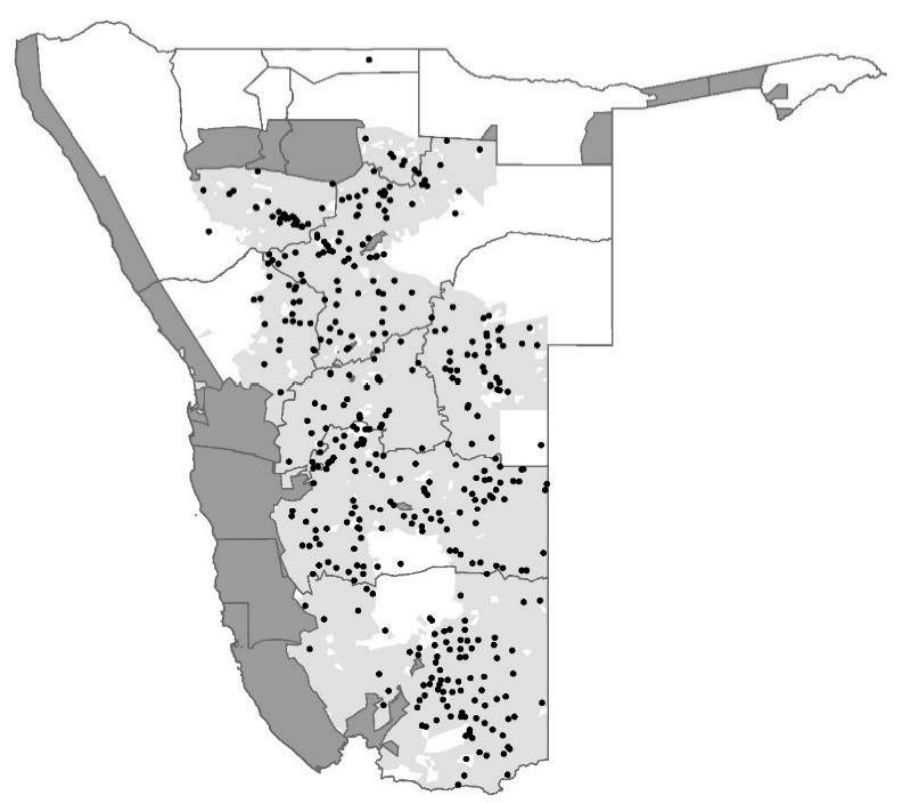

Figure 1. 


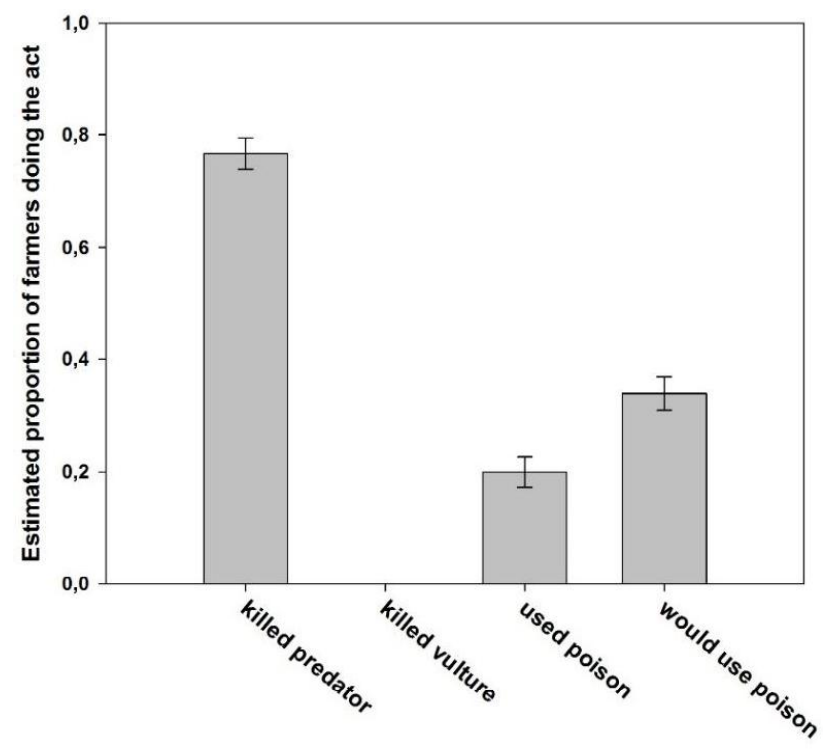

Figure 2. 


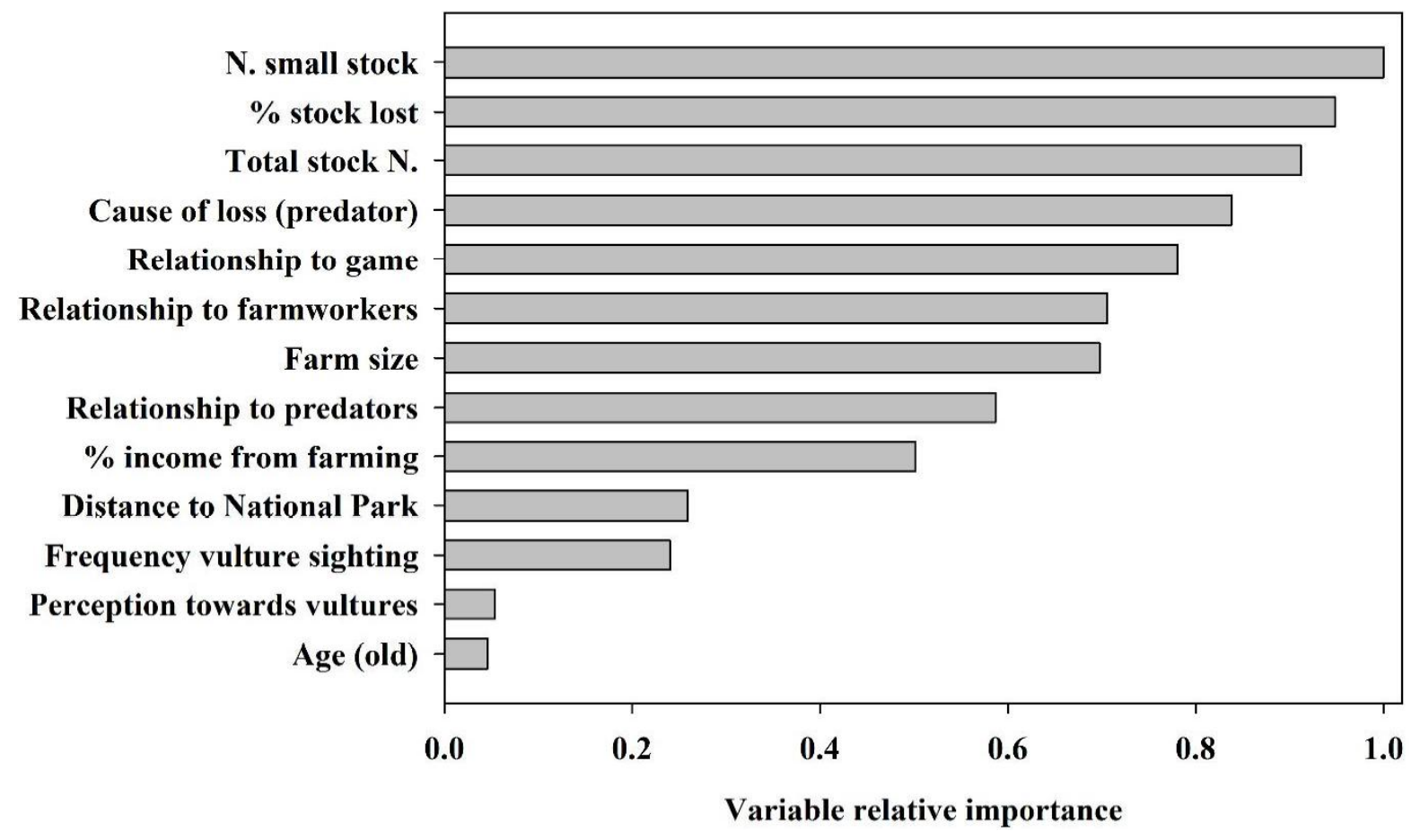

Figure 3. 


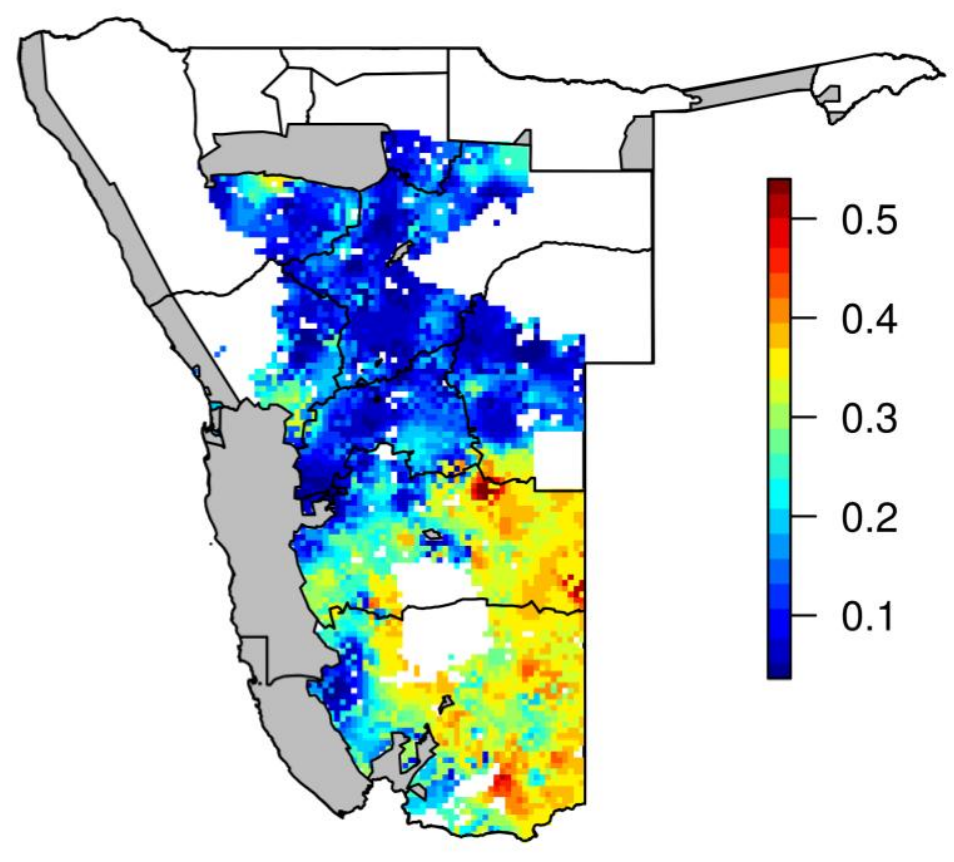

Figure 4. 


\section{Supporting Material:}

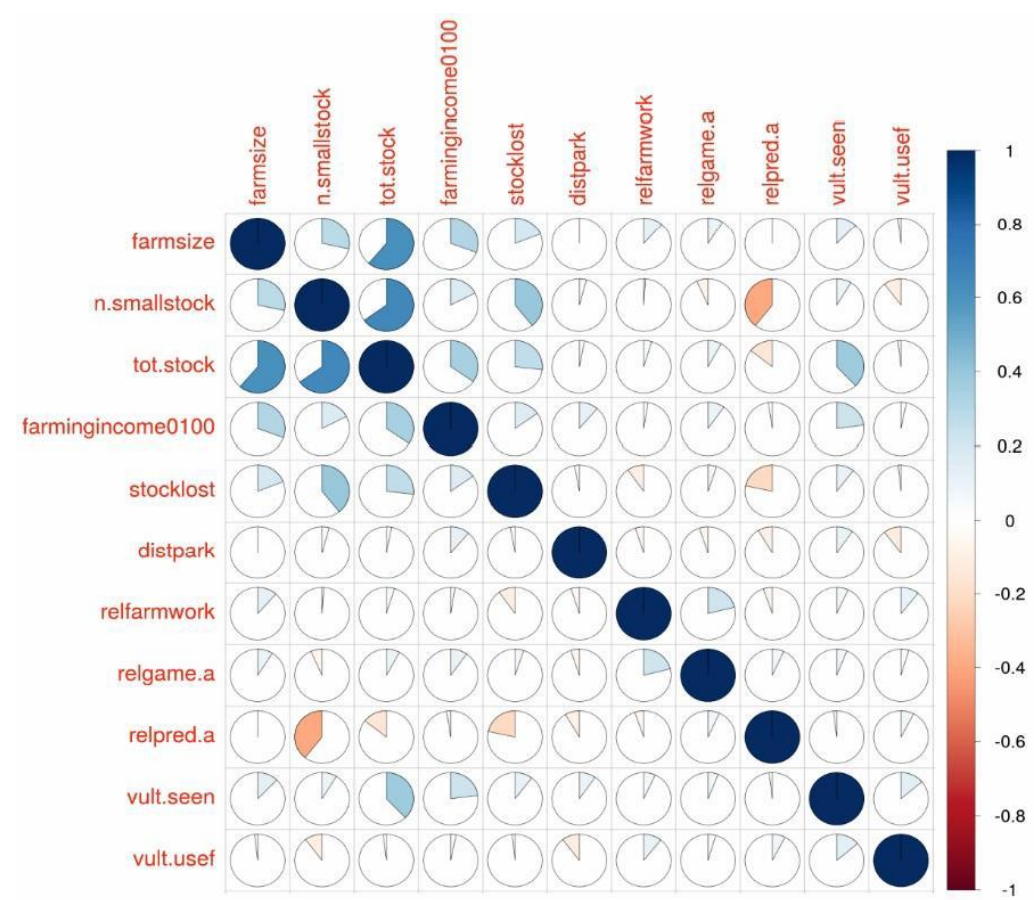

Figure S1. Extent of correlation between the 11 continuous variables derived from the questionnaire (see

Supporting Material Appendix S1) and included in the main model shown in Table 1 of the main manuscript.

Variables names, from left to right and from top to bottom refer to the variables names as presented in Table

1 of the main manuscript: Farm size, N. small stock, Total stock N., \% income from farming, \% stock lost,

Distance to National Park, Relationship to farmworkers, Relationship to game, Relationship to predators,

Frequency vulture sighting, Perception towards vultures, respectively. 

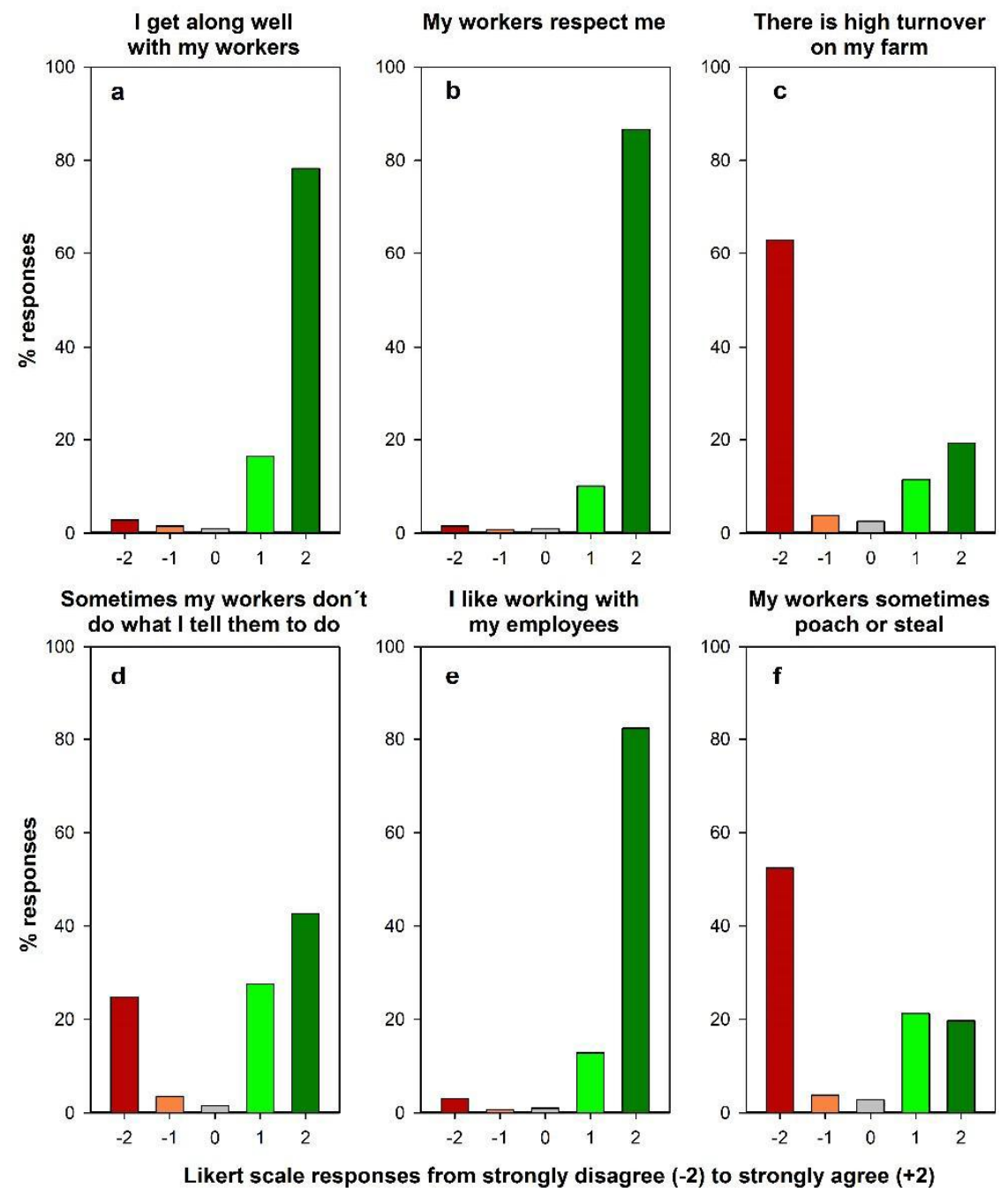

Figure S2. Answers to the six questions aimed to characterize the relationship between farmers and farm workers. Values of the bars represent the percentage of the responses given by farmers to each question following the levels of the Likert scale, from strongly disagree (-2), somewhat disagree (-1), neutral (0), somewhat agree (1), strongly agree (2). The panels above refer in turn to each statement (from a to f) under question 10 of the survey (see Appendix S1). The number of responses to each specific question (from a to $\mathrm{f}$ respectively) was: $397,397,395,397,397,396$. 

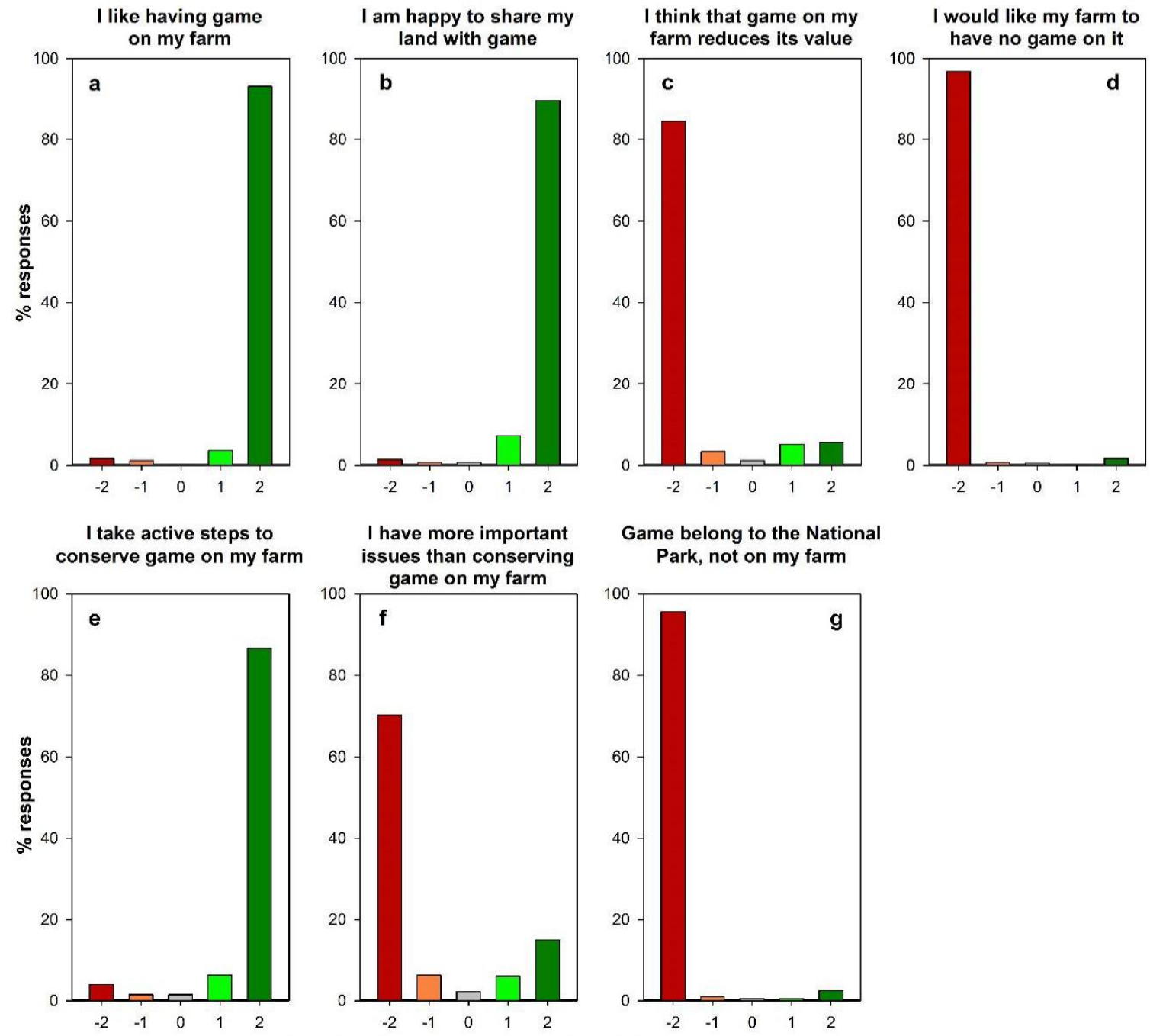

Game belong to the National Park, not on my farm

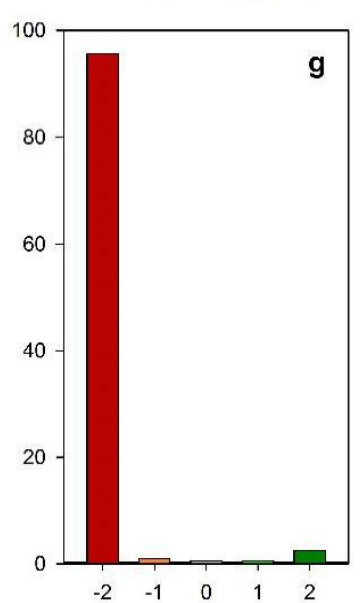

Likert scale responses from strongly disagree $(-2)$ to strongly agree $(+2)$

Figure S3. Answers to the seven questions aimed to characterize the perception of farmers towards game species. Values of the bars represent the percentage of the responses given by farmers to each question following the levels of the Likert scale, from strongly disagree (-2), somewhat disagree (-1), neutral (0), somewhat agree (1), strongly agree (2). The panels above refer in turn to each statement (from a to g) under question 11 of the survey (see Appendix S1). The number of responses to each specific question (from a to $g$ respectively) was: 408, 407, 407, 408, 407, 407, 408. 

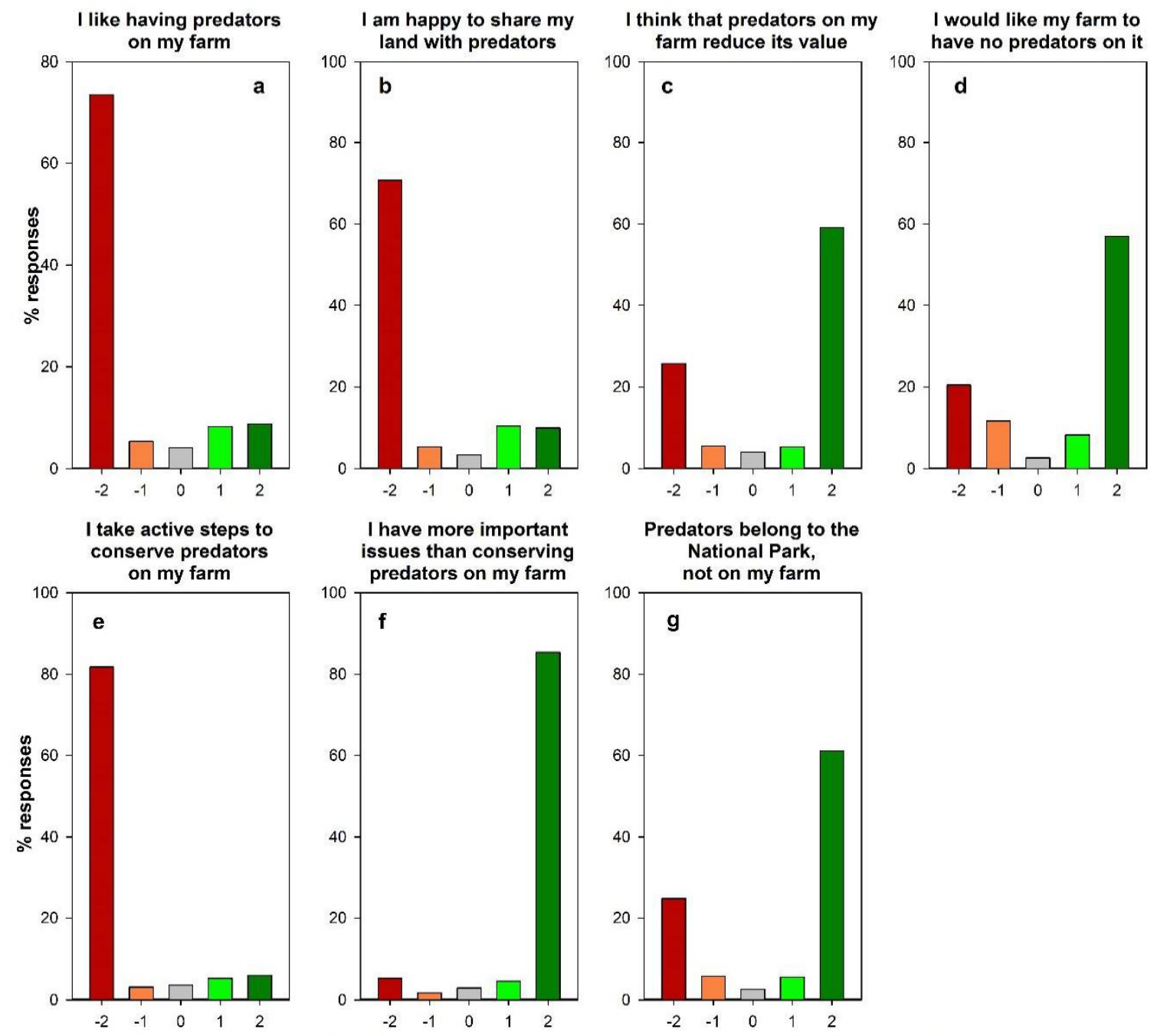

Likert scale responses from strongly disagree (-2) to strongly agree (+2)

Figure S4. Answers to the seven questions aimed to characterize the perception of farmers towards predators. Values of the bars represent the percentage of the responses given by farmers to each question following the levels of the Likert scale, from strongly disagree (-2), somewhat disagree (-1), neutral (0), somewhat agree (1), strongly agree (2). The panels above refer in turn to each statement (from a to g) under question 12 of the survey (see Appendix S1). The number of responses was 412 for each specific question (from a to $g$ respectively). 

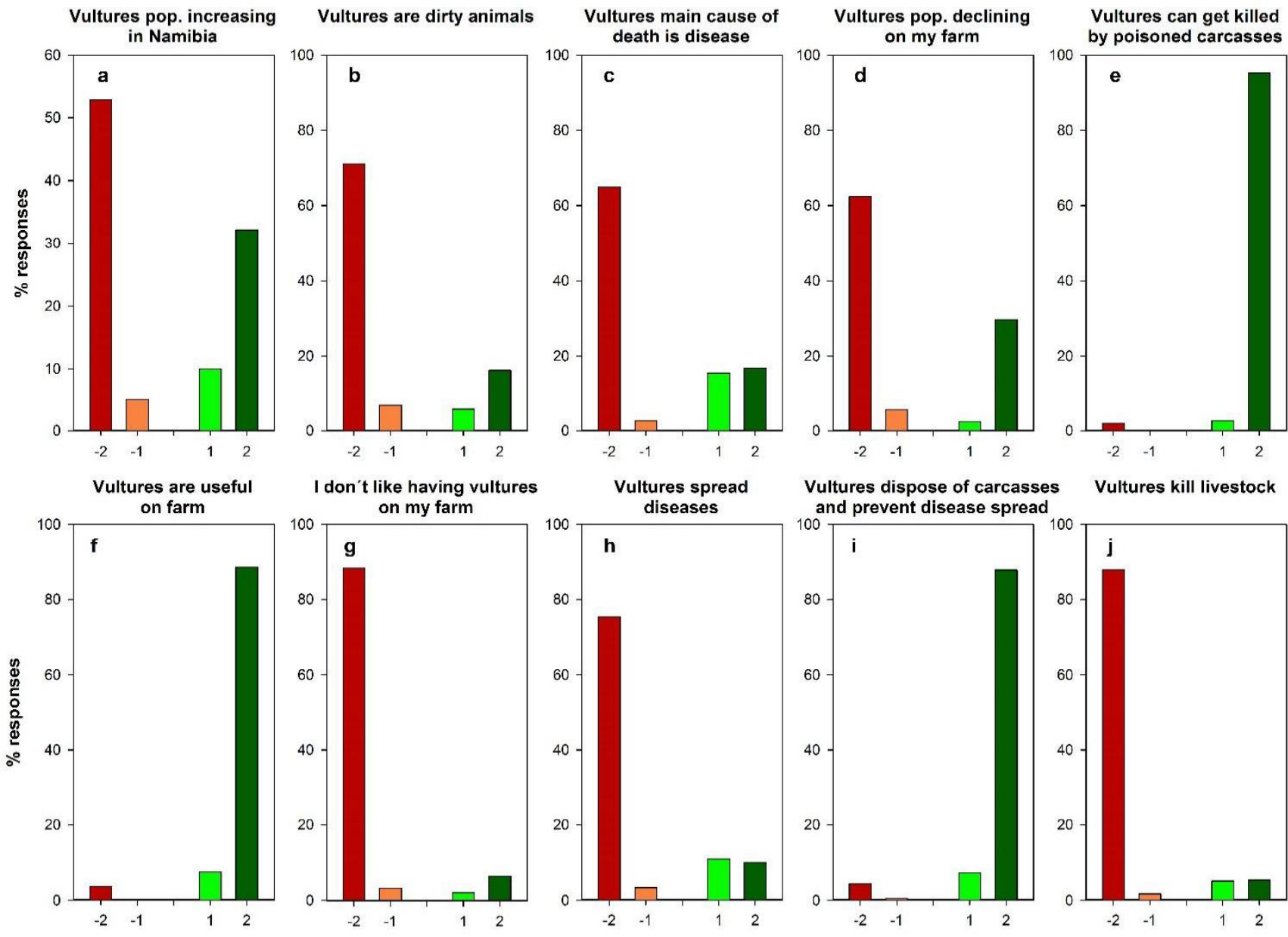

Figure S5. Answers to the ten questions aimed to characterize the perception of farmers towards vultures. Values of the bars represent the percentage of the responses given by farmers to each question following the levels of the Likert scale, from strongly disagree (-2), somewhat disagree (-1), somewhat agree (1), strongly agree (2). The value of zero on the Likert scale for this group of questions indicated "don't know", hence these responses are not presented here and the \% are based only on the sample of surveys where the response was not zero. The panels above refer in turn to each statement (from a to $\mathrm{j}$ ) under question 16 of the survey (see Appendix S1). The number of responses to each specific question (from a to j respectively) was: 327 , 283, 337, 330, 407, 407, 407, 368, 396, 411. 


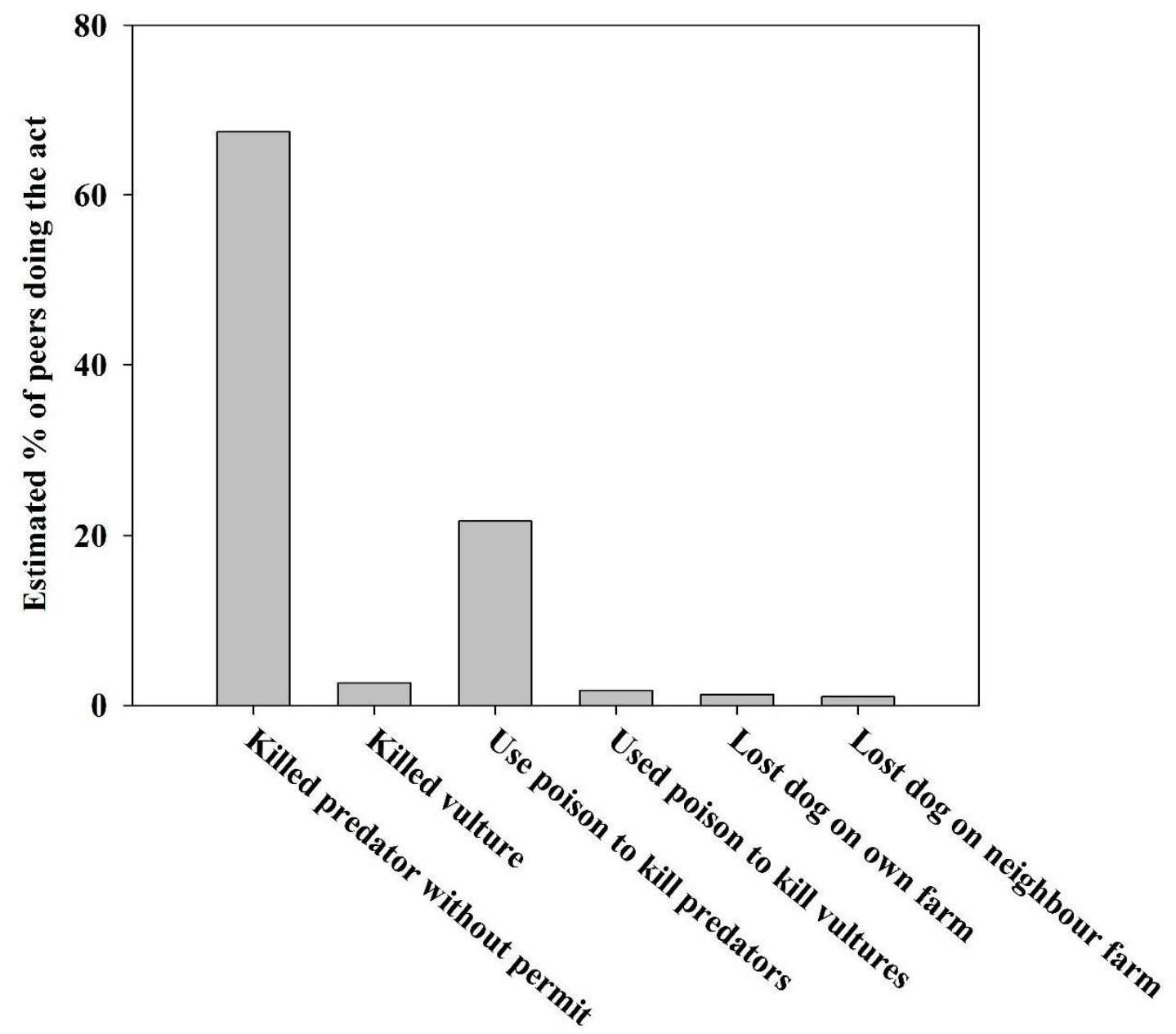

Figure S6. Farmers estimates of their peers' behavior on issues relative to killing predators and vultures, use of poison and whether they lost a dog because of poison use at the own or neighbor farm (questions 19.a-f in Appendix S1). 